\title{
MÉTODO(S) EM DIREITO COMPARADO
}

\author{
METHOD(S) IN COMPARATIVE LAW
}

Deo Campos Dutra*

\begin{abstract}
RESUMO
O presente artigo tem como objetivo principal realizar a análise do método em direito comparado. Para isso, o texto percorre algumas etapas. A primeira delas consiste em recuperar o debate sobre o sentido e a importância da metodologia e do método no âmbito do direito. Em um segundo momento dedica-se a analisar o conceito de método em direito comparado e oferecer ao leitor um rol não taxativo dos métodos utilizados no âmbito da disciplina. Por fim, e com o intuito de apresentar uma nova perspectiva ao leitor, o artigo alinha-se com a posição que entende que o direito comparado não possui um único método de comparação mais adequado e eficaz. Ao contrário, entende-se que há uma pluralidade de métodos em direito comparado, que são complementares e que podem inclusive ser utilizados de forma concomitante, para que a pesquisa comparada possa ter resultados mais rigorosos. A escolha do(s) método(s) a ser(em) utilizado(s) torna-se, assim, uma livre e legítima opção do pesquisador, variável conforme seus interesses científicos.
\end{abstract}

\section{PALAVRAS-CHAVE}

Método. Metodologia. Direito comparado.

\begin{abstract}
This paper aims to develop an analysis of the method used within comparative law. To achieve this objective, the research goes over some steps. The first one is to recover the debate about the meaning and importance of methodology and method under the law. The second moment is dedicated to analyze the concept of method within the comparative law framework and on giving the reader a nonexhaustive list of methods used in the subject. Finally, and in order to present a new perspective, the paper aligns with the position that considers that, in a comparative basis, comparative law does not have a single most appropriate and effective method. Instead, the paper argues that there is a plurality of methods in comparative law. They are complementary and can be used concurrently making comparative studies possible to reach more accurate results. The choice of the method(s) is, therefore, a free and legitimate choice of the researcher and will vary according to his/her scientific interests.
\end{abstract}

\section{KEYWORDS}

Method. Methodology. Comparative law.

\footnotetext{
* Doutor em Direito pela Université Paris Ouest Nanterre la Défense (Paris X) e pela PUC-Rio. Mestre em Ciências Jurídicas pela PUC-Rio. Pós-doutorando pela École Normale Supérieure - Paris. Professor e coordenador de pesquisa na Faculdade de Direito Doctum (Juiz de Fora, MG, Brasil).E-mail: deo_campos@yahoo.com.br

O autor agradece pela cuidadosa leitura e revisão do texto ao professor Dilton Ribeiro, pesquisador na Queen’s University, e aos revisores. As contribuições foram de fundamental importância para este trabalho.
} 


\section{INTRODUÇÃO}

“Levar o método a sério é levar o conhecimento (a epistemologia) a sério”. Com essa frase Geofrey Samuel inicia a conclusão da primeira parte de um dos seus mais importantes trabalhos, o artigo “Taking Methods Seriously” (2007, p. 118). Nesse trabalho o autor procura desenvolver, de forma detida, sobre a importância do método para o direito comparado. O cuidado com o método, prossegue, evita uma análise amadorística.

Segundo Samuel, para escapar dessa análise incompleta é fundamental pensar o direito comparado dentro de uma perspectiva epistemológica investigativa, driblando a perspectiva da autoridade normativa que é marca dos trabalhos de pesquisa que analisam o direito num panorama interno. Mas por que a metodologia, e consequentemente o método, esse temido companheiro dos pesquisadores, é tão importante para o direito comparado?

Essa é uma incômoda pergunta, que poucos pesquisadores do direito gostam de fazer. A complexa relação entre a pesquisa científica jurídica e os métodos utilizados por ela é bem conhecida da academia. Alguns autores alegam, inclusive, que a pesquisa jurídica é lamentavelmente marcada pela ausência do rigor do método, que, ao contrário, contribui de maneira importante em outras searas para uma melhor produção de conhecimento (LARENZ, 2014, p. 3).

Essa realidade, contudo, não pode ser expandida para todas as disciplinas jurídicas. O direito comparado vem há anos debatendo insistentemente questões relativas ao método. A comparação jurídica vem se firmando como uma ação profícua para esse tipo de questão. Esse debate se torna ainda mais importante na medida em que hoje comparar sistemas jurídicos distintos se tornou quase que compulsório para a pesquisa jurídica (VAN HOECKE, 2014, p. 1).

O objeto deste trabalho é justamente o método científico jurídico, especialmente no âmbito do direito comparado. Essencialmente, o que se almeja com este estudo é oportunizar ao leitor o debate existente atualmente na comunidade internacional sobre o método comparativo, seus desafios e novas perspectivas ${ }^{1}$.

De forma secundária e subsidiária, e com o intuito de complementar nosso objetivo principal, trataremos de forma crítica algumas das construções teóricas aqui apresentadas, sem, contudo, comprometermo-nos a exaurir esse tipo de análise.

\footnotetext{
${ }^{1}$ Aqui cabe uma fundamental ressalva, muito bem alertada por um dos avaliadores que analisaram este trabalho, e que o autor admite como imprescindível, desde já o(a) agradecendo por importante contribuição. Há, sem sombra de dúvida, uma prevalência da literatura europeia e norte-americana no texto. Isso, contudo, não obscurece a especificidade, importância e complexidade do debate realizado no âmbito da América Latina no que tange aos métodos em direito comparado. Esse debate, inclusive, é merecedor de estudo próprio. Para mais detalhes, ver BONILLA MALDONADO, 2009.
} 
Para alcançarmos esse propósito dividimos este texto em algumas seções. A primeira delas consiste em recuperarmos um debate de base e contribuirmos para a recuperação do sentido do termo “método”, sua importância e seu protagonismo no direito comparado. Assim, centraremos nossos esforços em resgatarmos um grupo de ideias a respeito dos sentidos e funções da metodologia nas ciências sociais, especialmente no campo do direito.

Posteriormente, pretendemos oferecer ao leitor uma breve, porém abrangente perspectiva de como o método é entendido no âmbito do direito comparado, analisando as contribuições de diversos autores para esse debate. Esses autores foram investigados em razão da centralidade de suas contribuições ao direito comparado, especialmente no que tange ao método em direito comparado.

Ao mesmo tempo pretendemos oferecer ao leitor aquilo que Mark Van Hoecke denominou de “caixa de ferramenta” do direito comparado. A intenção é apresentar alguns dos principais métodos, suas características e sua utilidade para o estudo comparado.

Por fim, avançaremos ao centro do debate, e pretendemos discutir a validade da utilização do método e seus possíveis procedimentos. Aqui, a intenção principal é desconstruir a ideia da existência de método perfeito para a análise comparativa e oferecer uma perspectiva que está vinculada à recente construção de Jürgen Basedow sobre a finalidade do método em direito comparado.

Em suma, nossa intenção com este trabalho não se resume a reavivar a importância do método na pesquisa científica no direito e seu protagonismo no âmbito do direito comparado - nossa finalidade é também oferecer ao leitor um verdadeiro rol de métodos que podem ser utilizados no âmbito da pesquisa jurídica comparativa.

Por fim, e consequentemente, pretendemos clarificar a importância da constatação de que não há um único método ideal de se fazer pesquisa comparativa, mas sim um conjunto de métodos que atuam paralelamente, de forma isolada ou em conjunto, e cuja eficácia varia de acordo com o objetivo do pesquisador.

Em síntese, pretendemos demonstrar que a importância do método se dá exatamente em razão das diversas possíveis contribuições que a pluralidade deles oferece ao estudo do direito comparado.

\section{METODOLOGIA E MÉTODO: SENTIDO E IMPORTÂNCIA}

Num dos mais clássicos estudos a respeito do tema, realizado em 1949, Boris Mirkine, mesmo que nutrindo uma acepção distinta de método em relação aos autores contemporâneos, alerta 
ao seu leitor que em todas as disciplinas sociais os problemas mais complexos estão exatamente na questão do método. O método, para esse autor, é a maneira de observar, de compreender e, sobretudo, de explicar. Vem daí a capital importância dos estudos metodológicos para as ciências jurídicas (MIRKINE-GUETZÉVITCH, 1949, p. 397).

A palavra metodologia é compreendida etimologicamente como a ciência ou o conhecimento sobre o método. Esse conceito, como podemos observar, oferece naturalmente uma ampla gama de questionamentos. Questões concernentes à tipologia do conhecimento ou sobre quais métodos a metodologia engloba nos levam a uma primeira constatação: a ciência sobre o método é uma “ciência multidirecional”. Em suma, existem diversas concepções a respeito daquilo que consideramos como metodologia (CHAMPEIL-DESPLATS, 2014, p. 2).

A primeira noção prática e concreta consiste, no âmbito do direito, em construir e oferecer modelos ou guias que permitam apurar a fundamentação das decisões de diversos sujeitos que são responsáveis por produzir normas jurídicas, como legisladores e juízes (CHAMPEIL-DESPLATS, 2014, p. 2). Esses modelos também já foram descritos como verdadeiras rotas para encontrar um determinado resultado pretendido, sendo a expressão metodologia entendida como “o estudo científico para encontrar essas rotas” (BERGEL, 2001, p. 17).

Nesse sentido, é importante desde já salientar que a metodologia jurídica não oferece à ciência jurídica “um catálogo conclusivo de técnicas de trabalho inquestionavelmente confiáveis, nem um sistema de hipóteses de trabalho que podem ser aplicadas genericamente e devem ser tratadas canonicamente” (MÜLLER, 2010, p. 27). Estar consciente dessa limitação não nos impede, é evidente, de averiguar a importância da formulação desses modelos.

Por outro lado, e numa acepção mais abstrata, a metodologia pode significar uma atitude que coloca em prática um processo de implementação de hipóteses particulares para encontrar uma explicação (CHEVALLIER, 1978, p. 82). Assim, ela se torna "uma forma de tecnologia onde o principal objetivo é de formular uma série de regras destinadas a guiar os especialistas em suas atividades de pesquisas, regras que para alguns constituirão formas de progresso do conhecimento”. Em suma, a metodologia ofereceria um “modelo de conhecimento científico” (VILLA, 1990, p. 28).

Nessa lógica, e no campo do direito, a metodologia centra-se essencialmente na análise dos métodos dos juristas que analisam o direito. Assim, a metodologia jurídica seria mais um discurso científico sobre um método científico. Seria, portanto, “uma forma de autoconhecimento feito pela própria ciência” (CHAMPEIL-DESPLATS, 2014, p. 3).

Para Hage, metodologia é o estudo dos padrões que são próprios para cada argumento científico. Não se trata, continua o autor, de um padrão ela mesma, mas, ao contrário, de uma 
disciplina que pertence, ou faz fronteira, com a filosofia da ciência e a ontologia (HAGE, 2014, p. 37).

Como veremos adiante, o estudo da metodologia científica está conectado intrinsecamente ao do direito comparado. O tema é um dos objetos centrais da disciplina e vem produzindo, no decorrer dos anos, uma farta literatura científica dedicada a ele (VAN HOECKE, 2004; MONATERI, 2012). Ao mesmo tempo, o estudo do método também é objeto de atenção dos comparatistas.

As palavras método e metodologia aparecem fundamentalmente conectadas com seu aspecto prático. Método significaria a maneira pela qual alguém empreende uma pesquisa científica. Numa segunda acepção, o método e a metodologia devem ser entendidos de forma distinta da substância da disciplina. Assim, no exemplo dado por Corten, “ensinar metodologia do direito internacional não é ensinar direito internacional” (CORTEN, 2009, p. 14).

Numa última acepção, e apesar dessa separação, a escolha de certos métodos implicaria a escolha de certa perspectiva teórica. Consequentemente, o estudo da metodologia não estaria situado exclusivamente no campo da epistemologia, mas também no campo da teoria. Dessa forma, estudar diferentes teorias requer lidar com diferentes métodos (SAMUEL, 2014, p. 2).

A palavra método, por sua vez, expressa a própria versatilidade do vocábulo. Ela tem origem no termo grego que significa a junção das palavras metá (após) e odós (que significa caminhar por uma certa rota) (HUSA, 2015, p. 55). A dicção refere-se a um caminho, a uma direção a seguir, um conjunto de processos intelectuais mais ou menos complexos que permitem encontrar um objetivo determinado (BOBBIO, 1994, p. 165).

O termo posteriormente deu origem ao latim "methodos", que significa "modo de proceder", “procedimento racional” e "sistema de classificação", e ao francês "méthode", que se refere a “procedimento racional”. Numa linguagem moderna, ele teria dois sentidos principais. O primeiro estaria ligado à descrição de uma maneira para alcançar certos objetivos, enquanto o segundo estaria vinculado a uma qualidade de ser bem organizado e sistematizado no pensamento ou ação (GLANERT, 2012, p. 65).

Métodos “constituem de maneira mais ou menos abstrata, concreta, precisa ou vaga, um plano de trabalho em razão de uma meta específica” (GRAWITZ, 2001, p. 352). De uma maneira entendida como pedagógica, são ilustradas quatro concepções de método.

A primeira delas está num nível filosófico e tem como sentido um conjunto de operações intelectuais pelas quais uma disciplina procura alcançar as verdades que ela persegue. Numa segunda concepção, conecta-se a uma ideia de “atitude concreta face a um objeto de análise”. Aqui, mais do que a um método específico, seu sentido está ligado a um grupo de tipos de métodos que estão 
integrados a certos programas metodológicos, mais ou menos concretos, que são elaborados com o intuito de determinar as etapas da pesquisa e que variam de acordo com os objetos estudados (GRAWITZ, 2001, p. 352).

Um método também pode ser entendido como “esquemas de explicação” que podem se colocar de maneira mais ou menos expandida e situarem-se num nível de profundidade diferente. $\mathrm{O}$ método dialético, em que há uma exposição de argumentos pró e contra com uma conclusão; o funcionalista, em que se faz uma acentuação da função ocupada pelos objetos estudados; o sistemático, em que há a apresentação de um objeto como parte de um sistema; o sintético, em que há a acentuação naquilo que é essencial para a análise; e o analítico, em que se acentuam os elementos distintivos, são exemplos desses esquemas (CHAMPEIL-DESPLATS, 2014, p. 4).

Por fim, há a noção de método como um domínio particular. Esse sentido está conectado às especificidades de certas disciplinas, de certos domínios particulares do conhecimento. Como exemplo dessa perspectiva, podemos destacar o método histórico, o psicanalítico, o sociológico e o jurídico (GRAWITZ, 2001, p. 352).

No direito comparado o método se destaca por um importante papel - como parte integrante de um processo de pesquisa que necessita de sua utilização para encontrar as respostas pretendidas. Não é possível se pensar no exercício do estudo do direito comparado sem a identificação, escolha e aplicação de um determinado método.

Este “guia” para a pesquisa científica pretende garantir, fundamentalmente, um trabalho cientificamente rigoroso. Ele será considerado exigente exatamente por ter sido desenvolvido conforme padrões que darão suporte à conclusão final de seu autor. A utilização de um determinado método significa, portanto, a garantia de identificação de uma relevante e segura informação ao final da pesquisa (HAGE, 2014).

A importância do método não é contestada por nenhum autor do direito comparado. O problema surge exatamente no momento em que alguns autores insistem em condicionar a disciplina do direito comparado como expressão apenas de um método exclusivo.

Isso porque, ainda hoje, aqueles que identificam o direito comparado como método não conseguem oferecer a resposta sobre qual seria o método do direito comparado, deixando, no máximo, uma resposta vaga para a questão (ÖRÜCÜ, 2007, p. 62).

O direito comparado, como disciplina jurídica², pretende encontrar suas respostas científicas utilizando-se de um processo de pesquisa que perpassa a escolha e aplicação de um ou de vários

\footnotetext{
2 Para o direito comparado como disciplina jurídica, ver EBERLE, 2009; HUSA, 2015, p. 53; SAMUEL, 2014, p. 13; BASEDOW, 2014.
} 
métodos jurídicos comparados.

Sendo assim, como vimos, é preciso entender o que expressamos quando falamos no termo método. É preciso, também, entender o que não dizemos com o uso do vocábulo.

\subsection{O QUE O MÉTODO NÃO É?}

Diante de tantos sentidos, a palavra método pode perder muito de sua centralidade e importância caso haja uma leitura apressada do termo e de sua aplicabilidade na pesquisa do direito comparado. Uma importante contribuição nesse debate parte da adoção de um caminho distinto nessa árdua tarefa de conceituação.

Segundo Glanert, é preciso compreender, antes de mais nada, o que o método não é. Essas ideias, ao contrário da tradicional passagem feita pelos autores, opõem-se à ideia de método como caminho para o conhecimento e do sentido do método como primordialmente epistemológico (GLANERT, 2012, p. 61).

Essa opção, por outro lado, mesmo parecendo se afastar da maioria da doutrina, aproximase em vários momentos de diversas e importantes observações sobre aplicabilidade do método na pesquisa comparada. Ela também nos auxilia no complexo processo de entendimento que devemos ter do termo e nos impõe importantes reflexões que são úteis para o melhor entendimento e uso do método e da metodologia na pesquisa.

A primeira assertiva da autora afirma que o método não é “pan-disciplinar”. Isso significa, na esteira de Agamben, que o método não pode ser separado de seu contexto. Assim, como na lógica não há método que possa ser válido para todo o domínio do conhecimento, não há lógica que possa prescindir de seu objeto (AGAMBEN, 2009, p. 7). Dessa maneira, há uma infinidade de métodos que podem ser identificados em cada formação disciplinar, e uma verdadeira pluralidade de métodos que podem ser utilizados. Basta observarmos o contexto.

Ao mesmo tempo, para a autora, um método não pode ser considerado como absoluto. Essa afirmação é condizente com a mais recente doutrina que analisa a metodologia na perspectiva do direito comparado.

Há, fundamentalmente, uma diversidade de métodos em cada disciplina, e no direito comparado não é diferente. Atualmente vem ganhando prevalência no campo doutrinário a perspectiva interdisciplinar. Nesse sentido, "faz-se necessário que os comparatistas analisem os diversos métodos razoáveis, diversos esquemas de inteligibilidade, paradigmas e perspectivas epistemológicas que são aplicáveis nas ciências e nas ciências sociais” (SAMUEL, 2007, p. 236). 
O método também não é objetivo. Apesar de suas iniciais aspirações, o fato é que todo método é produzido por um indivíduo particular, situado num determinado tempo e espaço. Como salienta Glanert (2012, p. 68), “todo método é o método de alguém”. Há, portanto, uma inevitável subjetividade que não pode ser negada quando falamos de método.

No mesmo sentido e além, o direito comparado, em si, não pode ser considerado neutro. Ele tem uma característica intrinsicamente intencional em seu trabalho, especialmente em projetos como o mapeamento do mundo em sistemas legais (MONATERI, 2012, p. 10).

Por fim, não podemos deixar de afirmar que todo método é especulativo. Todo trabalho acadêmico, apesar da ambição claramente contrária, lida com o domínio da representação. Como cada representação é gerada por um observador situado, é inevitável que ela contenha uma descrição (BERCEA, 2009, p. 41).

Assim, não podemos desconsiderar que o direito comparado também está afetado por esse fato. A lei estrangeira, portanto, objeto de estudo dos comparatistas, é, ao fim e ao cabo, transformada na própria linguagem do estudioso. Essa transformação é inevitável, por maiores que sejam os esforços em sentido contrário (GLANERT, 2012, p. 69).

Essa perspectiva sobre o método, convergente a uma teoria hermenêutica crítica liderada por Pierre Legrand a partir da França, pode ser em diversos sentidos questionada e até repelida (LEGRAND, 1999).

Ela, contudo, não deixa de acrescentar, de maneira importante, uma perspectiva que nos ajuda a entender melhor o conceito e o sentido deste controverso termo. Compreender a complexidade do sentido do termo método, suas áreas nebulosas e possíveis fraquezas, auxilia-nos a entender melhor o que queremos afirmar quando dizemos método(s) em direito comparado.

\section{MÉTODO EM DIREITO COMPARADO}

A dificuldade em identificar um único conceito confunde-se com o obstáculo em determinar um único caminho metodológico para a pesquisa em direito comparado. Essa realidade levou diversos estudiosos a um debate infrutífero na busca por uma possível “solução metodológica ideal”, o que resultou em muitos e importantes estudos, mas pouco avanço nesse campo do direito.

Hoje há um consenso entre os estudiosos, de que o trabalho de pesquisa no campo dessa ciência jurídica precisa ser rigorosamente pautado por uma metodologia específica. Isso não significa, contudo, que existe um único método possível.

Na verdade, autores clássicos já havia alertado para tal fato. Constantinesco, por exemplo, 
já havia afirmado que não existiria um método próprio ao direito comparado. Entretanto, ele não vai além.

Para o autor, os comparatistas fazem os mesmos caminhos que os juristas nacionais, além de operarem com os mesmos métodos. A diferença estaria na atenção dada pelos comparatistas à busca por novos olhares, distintos daqueles dos juristas que centram seus esforços no direito interno (CONSTANTINESCO, 1974, p. 329).

Ao mesmo tempo, há hoje um consenso colocado: não há apenas um caminho que nos leva ao sucesso da empreitada comparatista, mas vários. Devemos falar, portanto, em métodos de direito comparado (JALUZOT, 2005, p. 44). Nesse sentido, haveria tantos métodos quanto comparatistas, ou, ao menos, o mesmo número de métodos e de conceitos em direito comparado (MONATERI, 2012).

Para Adams, por exemplo, não é possível falar em metodologia do direito comparado. O autor entende, inclusive, que não se presta nenhum serviço em procurar uma resposta para essa questão. O direito comparado, completa, “é uma coleção de métodos que podem ser úteis na busca para respostas de diversas questões ligadas ao direito” (ADAMS, 2011, p. 236). As escolhas metodológicas estariam conectadas aos objetivos da comparação e dependentes deles. O objeto e a finalidade perseguidos pelo comparatista são opções, portanto, interdependentes (PONTHOREAU, 2010, p. 61).

Glenn chega a afirmar que a história do direito comparado é justamente a história da não aderência a um determinado método científico, “de afastamento e variação” de métodos (GLENN, 2014, p. 177).

Há, portanto duas posições que se completam. A primeira delas compreende a fundamentalidade da escolha de um método para o trabalho de pesquisa no direito comparado. A segunda ressalta que, ao contrário do que foi pensado durante muitos anos, não há um único método correto, mais eficaz e, portanto, universal, para a realização dos estudos comparados.

Conscientes dessa realidade, os estudiosos do direito comparado centram atualmente suas atenções não só no desenvolvimento de caminhos metodológicos mais adequados e que possam potencializar os resultados do trabalho de pesquisa que estão desenvolvendo.

Há, hoje, uma série de esforços no sentido de sistematizar os métodos até então apresentados, seu valor, características e fragilidades. A pergunta, portanto, também é: Quais são os métodos em direito comparado? Quais são suas funções?

Como resposta a esse questionamento, Hoecke identificou seis diferentes métodos de pesquisa comparativa: o método funcional, o analítico, o estrutural, o histórico, o contextualizado 
(law in context) e o método do núcleo comum (common core). Esses métodos, como vimos acima, aproximam-se como “esquemas de explicação”, salientados por Champeil-Desplats a partir do trabalho de Grawitze e utilizados na metodologia jurídica tradicional.

Cada um deles possui suas peculiaridades, forças e pontos discutíveis. Todos, cada um diante de uma necessidade específica oriunda do pesquisador, são de grande valia para o trabalho do comparatista.

Esta lista não é um rol taxativo. Tampouco podemos afirmar que a utilização de um desses métodos significa necessariamente a exclusão de outros na mesma pesquisa. Ao contrário, é possível, e muitas vezes imprescindível, a aplicação de dois ou mais métodos numa mesma investigação. Eles compõem aquilo que chamaremos de métodos fundamentais para a pesquisa comparatista.

O primeiro, e ainda predominante, método comparativo é até hoje objeto de extensa polêmica no debate em torno do método no direito comparado. Ele é denominado de método funcionalista, e tem no trabalho dos professores alemães Konrad Zweigert e Hein Kötz sua maior expressão. Segundo os autores, esse seria o principal método para o direito comparado (ZWEIGERT; KÖTZ, 1998, p. 34).

O método funcionalista pode ser definido como aquele que pretende identificar respostas jurídicas similares ou distintas, em conflitos sociais que se assemelham mesmo ocorrendo em lugares distintos no mundo. A solução legal para problemas correlatos em diversas partes do mundo pode ser aparentemente distinta, mas possui uma “equivalência funcional”, já que esses mesmos problemas como, por exemplo, acidentes, contratos, mortes - são praticamente idênticos em todo o mundo.

O trabalho desses autores possui como principal característica a construção de quatro proposições. A primeira delas é a concepção de que a lei pode ser descrita de maneira afastada da realidade humana. Apesar da inevitável interferência, na lei, pelos fatos da vida, essa poderia ser compreendida de maneira isolada e conceitualmente distinta (ZWEIGERT, KÖTZ, 1998, p. 31).

A segunda proposição tem uma dimensão sociológica (VALCKE; GRELLETTE, 2014, p. 99). Para os autores, os problemas que a lei pretende resolver são primordialmente idênticos em todo o mundo. Como consequência, surge a terceira proposição. Se as leis existem para resolver problemas que são, em sua essência, comuns em todo o mundo, então as leis também seriam similares em todo o mundo (ZWEIGERT; KÖTZ, 1998, p. 32).

Por fim, a quarta e última proposição que sustenta o método dos autores é a chamada "tese de convergência”. Essa tese pressupõe que, mesmo que o mundo não possa de fato ser descrito como foi pela terceira tese, cabe ao direito comparado fazê-lo (ZWEIGERT; KÖTZ, 1998, p. 30).

Numa síntese apertada, a agenda dos funcionalistas pode ser entendida como aquela que 
transita por uma linha de raciocínio que compreende que a lei ao redor do mundo pode ser conectada a uma função considerada central e externa a ela. Essa lei, por sua vez, procura solucionar o mesmo grupo de problemas sociais. Assim, faz sentido pensar que, em última análise, há um sistema global contendo todas as regras que melhor respondem a determinada tarefa cujo objetivo de fundo é comum (VALCKE; GRELLETTE, 2014, p. 100).

Apesar de muito criticado pelos estudiosos, o funcionalismo ainda permanece, sem dúvidas, como o "epicentro” do método em direito comparado (PLATSAS, 2008, p. 1). Essa centralidade se dá não porque o método tenha uma consistência teórica clara e convincente. A razão principal é que o funcionalismo contribui de maneira importante e prática à identificação de algum tipo de similaridade ou de diferença entre os sistemas legais estrangeiros, contribuindo para o trabalho de pesquisa do comparatista (GORDLEY, 2012, p. 107).

De qualquer maneira, o termo “método funcionalista” possui três inconveniências em seu sentido. A primeira delas é que não há um único método funcionalista. Em segundo lugar, nem todos os alegados métodos funcionalistas podem ser considerados essencialmente funcionalistas. Por fim, alguns projetos que alegam estarem filiados ao método nem sequer podem ter identificado algum método reconhecido em seu trabalho ${ }^{3}$.

Por outro lado, existem alguns elementos importantes do funcionalismo que são convergentes a todos os seus defensores. A primeira convergência está centrada na factualidade do método. O funcionalismo estaria focado não nas regras, mas em seus efeitos; não nas estruturas e argumentos da doutrina, mas nos eventos. Uma segunda pacificidade concerne à combinação da ideia de que a perspectiva factual deve ser entendida “sob a luz da sua relação funcional com a sociedade”.

Consequentemente, a função acaba servindo ela mesma como um "tertium comparationis", ou seja, instituições, tanto jurídicas como não jurídicas, mesmo que doutrinariamente diferentes, podem ser comparáveis caso sejam funcionalmente equivalentes, por preencherem funções similares em diferentes sistemas legais.

Por fim, e como quarto elemento, desta vez não compartilhado por todas as variantes do método funcional, há o entendimento de que o método funcional pode servir como critério de avaliação. Dessa maneira, o método comparativo tornar-se-ia um “better-law comparison”; ou seja, a melhor entre as diversas leis é aquela que preenche a sua função de maneira mais adequada que todas as outras (MICHAELS, 2008 p. 342).

Uma importante crítica ao funcionalismo entende que os problemas visados pelas leis são eles mesmos uma questão de construção social. Sendo assim, toda e qualquer ligação entre as soluções

\footnotetext{
${ }^{3}$ Para mais detalhes, ver MICHAELS, 2008, p. 342.
} 
encontradas pelas leis em cada sistema jurídico é meramente alusiva. Cada problema, assim como cada solução, variará em qualquer sociedade, ou seja, será particular. Alguns críticos vão além e argumentam que o que há, de fato, é uma falácia funcionalista, na medida em que essa visão não consegue ser mais que “superficial” (FRANKENBERG, 2006, p. 444).

Como resultado, por mais que o funcionalismo possa encontrar proximidades entre sistemas que possuem um mesmo contexto social e histórico, como o da Europa Ocidental, por exemplo, ele terá grandes ou até mesmo intransponíveis desafios para fazer o mesmo no restante do mundo. Não seria possível, portanto, aplicar o método funcionalista com verdadeiro sucesso sem a complementação de outros métodos, como a contextualização, por exemplo (VAN HOECKE, 2014, p. 10).

Entre seus críticos, uma importante perspectiva foi desenvolvida de forma a contrastar com o funcionalismo. Na esteira dos estudos que tratam da análise econômica do direito, foi concebida a ideia de uma análise econômica do direito comparado (MATTEI, 1999).

A ideia principal dessa metodologia é iniciar a comparação numa escala considerada neutra. Dessa forma, ela poderá ser validada por meio do padrão da eficiência econômica. O termo eficiência, em seu sentido comparado, é definido como qualquer tipo de arranjo legal que outros sistemas jurídicos possuem e que, por serem melhores que o do sistema em que estamos inseridos, devem ser estudados e/ou incorporados (MATTEI, 1999, p. 145).

O “comparative law and economics” dedica-se, assim, à identificação de pontos de convergência e divergência e à ocorrência de transplantes legais entre sistema legais. Ele procura explicar as convergências e divergências como resultado de uma "competição entre sistemas legais” (OGUS, 1999, p. 406).

A diversidade legal, de acordo com o “comparative law and economics”, é resultado da transação de custos da tradição, cultura e ideologia (MATTEI, 1999, p. 121), e seu principal instrumento de comparação é a análise analítica (BRAND, 2007, p. 421).

O método analítico funda-se, principalmente, na ideia de que, mesmo que existam conceitos jurídicos muito próximos, é possível identificar, numa análise mais detida e segundo o contexto em que estão inseridos, diferenças importantes entre eles.

Assim, segundo o método analítico, não é possível desconectar nenhum conceito jurídico das regras do sistema jurídico ao qual ele pertence. O conteúdo de um conceito jurídico é definido pelas regras vigentes que regulam a matéria abrangida pelo conceito; em particular, um determinado sistema jurídico num certo lapso determinado no tempo (VAN HOECKE, 2014, p. 14).

Entretanto, algumas vezes podemos detectar pequenas diferenças, e algum tipo de conteúdo 
comum pode ser identificado, em conceitos como “vontade” e “estado”, entre outros. Essa é a razão que faz com que alguns autores argumentem pela existência de conceitos que são "dependentes do sistema” e conceitos que são “relativamente independentes do sistema” (FRÄNDBERG, 1987, p. 88).

No que diz respeito à profundidade da comparação, tanto o método funcional quanto o analítico se propõe a realizar um trabalho de comparação que é designado de “microcomparação”. A microcomparação centra seus esforços numa atividade que deve ser executada num nível mais profundo, em que as diferenças mais fundamentais entre os sistemas jurídicos e regulações são levadas em consideração (VAN HOECKE, 2014, p. 21). Trata-se, sobretudo, de um trabalho em uma escala reduzida, centrando as atenções em leis específicas, em termos selecionados ou em problemas determinados (HUSA, 2015, p. 57).

O mesmo não se dá com o método estrutural. O método estrutural é aquele que pretende analisar toda a estrutura e relações entre diferentes sistemas jurídicos. Diferenças entre sistemas jurídicos num determinado ponto específico podem perder sua importância e relevância se elas dividem uma semelhança estrutural, como, por exemplo, princípios de direito romano ou conceitos de direito privado.

Assim, podemos classificá-los como membros de uma mesma tradição, família ou sistema jurídico, e colocá-los em oposição a outras famílias que não possuem essas mesmas semelhanças.

Trata-se, assim, de uma macrocomparação. A macrocomparação compara, em uma escala maior, a função dos sistemas jurídicos e suas características fundamentais (HUSA, 2015, p. 58). Exemplos notáveis de comparação estrutural no campo do direito comparado podem ser encontrados em David (2002), Losano (2007) e Glenn (2014).

A análise estrutural pode ser feita de diversas maneiras, com base numa ampla variedade de distinções e critérios. Num nível considerado mais profundo podemos até afirmar que todos os sistemas jurídicos possuem um núcleo comum, que está conectado com a definição de lei, como um sistema identificado em toda a sociedade (VAN HOECKE, 2014, p. 12).

Um dos autores que se dedicou ao estudo do método em direito comparado é o professor alemão Günther Frankenberg, ligado à escola crítica do direito. A motivação do professor em buscar construir um novo método de pesquisa em direito comparado tem origem na sua negação do funcionalismo e sua presunção de necessidade e universalidade. A notável intenção do professor é transformar o direito comparado convencional num instrumento de crítica ao direito (BRAND, 2007, p. 433).

Para isso, ele divide o processo comparativo em três momentos. No primeiro deles requerse que o comparatista escrutine de forma cuidadosa o que acontece quando as múltiplas facetas de 
uma situação factual são retiradas de seu contexto social e colocadas dentro de um quadro legal.

O segundo passo é clarificar esse quadro legal mediante uma detida análise crítica de sua estrutura e investigar o seu processo de tomada de decisão. Esse processo possibilitaria, segundo o autor, uma análise da dimensão política da norma.

Somente com este tipo de cuidado - a procura pelo político dentro do direito - o comparatista poderá ultrapassar as tradicionais concepções do discurso legal, como direito e deveres, e encontrar o político. Ao encontrar o discurso político, completa o autor, o comparatista pode identificar as agendas de dominação e hegemonia que estão inseridas por trás de cada norma e realizar melhor seu trabalho (FRANKENBERG, 1997, p. 261).

No terceiro e derradeiro passo, o comparatista deve reintroduzir o contexto sociocultural que foi perdido na legalização do problema. Assim, a intenção do autor é justamente fazer com que o estudioso do direito comparado tenha uma maior preocupação com a identificação e valorização da diferença entre os sistemas, e não com suas similaridades.

Esse processo intelectual daria ao pesquisador um espaço para a construção de um pensamento sensível à diferença e de respeito pelo outro, construindo um espaço de tolerância. E, ao mesmo tempo, produziria um importante comportamento autocrítico, essencial para a produção de conhecimento (FRANKENBERG, 1985, p. 441).

Esse perscrutador processo desenvolvido pelo professor alemão se utiliza do método por nós designado como “método de comparação contextualizado" (em inglês, "law in context”) - nossa quarta proposição. Esse método entende que não é possível, sem um processo rigoroso de contextualização, fazer uma análise comparativa.

Da mesma maneira, ele tem como uma de suas características principais a impossibilidade de ser aplicado de forma isolada em relação aos outros. Trata-se, portanto, de um método que necessariamente será conjugado com outro, em um processo de comparação. Essa metodologia procura sofisticar a análise comparativa, atuando em conjunto com os outros métodos na procura por um maior entendimento da normativa trabalhada.

Apesar de algumas formas de comparação analíticas poderem ser desenvolvidas de maneiras mais abstratas e, portanto, mais desconectadas da realidade social, outros métodos de comparação, como o funcionalista e o estrutural, normalmente se utilizam constantemente da contextualização.

Essa comparação contextualizada, por sua vez, pode ser realizada de diversas maneiras. Ela pode apontar apenas de forma geral a um contexto existente, como o tipo de sistema econômico que determinado Estado adota, e, consequentemente, aos seus reflexos no sistema jurídico. Pode ainda ser realizada uma contextualização mais específica, utilizando dados históricos, sociológicos ou 
antropológicos. Por fim, pode ser produzido um verdadeiro estudo interdisciplinar, com diversas disciplinas, fora do âmbito da ciência jurídica, usadas em conjunto com o direito. Tudo dependerá da intenção e do foco da pesquisa, além, é claro, da quantidade de informação e conhecimento que o pesquisador possui em mãos para o desempenho da pesquisa comparativa (VAN HOECKE, 2014, p. 16).

Outro importante expoente que produz suas comparações com base nessa opção metodológica é o professor Rodolfo Sacco. Em seus estudos sobre transplantes jurídicos, a contextualização ganha importância e destaque, e fica evidenciada na medida em que parte de suas conclusões convergem no sentido de compreender que as regras constitucionais, a doutrina e até elementos implícitos dos sistemas jurídicos, como a visão de mundo e a cultura, influenciam de maneira significativa no modo como o direito é interpretado e manipulado (SACCO, 1991).

O método histórico, por sua vez, pode ser considerado como parte do método de contextualização. O contexto aqui, está ligado às origens históricas das leis atuais, que são comparadas. A compreensão atual mais completa possível de uma lei e suas funções em uma sociedade só é possível se entendermos sua origem e as razões que levaram ao seu surgimento.

Informações e fontes históricas são geralmente mais acessíveis aos estudiosos. Grande parcela das doutrinas hoje disponíveis contém, inclusive, parte de seu trabalho dedicada a uma análise histórica. Esse estudo, ao mesmo tempo, faz uso de perspectivas sociológicas, políticas e até psicológicas, que compõem o contexto histórico estudado, sofisticando o trabalho de pesquisa.

Esse tipo de trabalho pode oferecer ao pesquisador mais do que explicações a respeito das origens e razões pelas quais as leis alcançaram seu conteúdo e formato atual. Ele pode, em alguns casos, revelar que leis, que hoje fazem parte de um sistema jurídico, já estiveram, em épocas anteriores, presentes em outros sistemas.

Ao mesmo tempo, esse método pode contribuir para identificarmos diferenças em determinados estágios de desenvolvimento dos sistemas jurídicos. Da mesma forma, o método auxilia a apontar tensões entre maneiras distintas de solucionar problemas jurídicos que prevaleceram de maneiras diferentes em diversos sistemas. Assim podemos, por exemplo, reconhecer a preponderância de respostas jurídicas mais alinhadas com perspectivas políticas de esquerda ou de direita (VAN HOECKE, 2014, p. 18).

Esse método de comparação pode, certamente, cooperar de maneira significativa para revelar similaridades e diferenças entre sistemas jurídicos que não estavam sendo observadas, contribuindo para uma comparação num "nível mais profundo”, evitando-se resultados superficiais

\footnotetext{
${ }^{4}$ Sobre Deep Level Comparative Law, ver VAN HOECKE, 2004, p. 165.
} 
Por fim, o método do núcleo comum tem como principal motivação a identificação de pontos que são similares em diversos sistemas jurídicos. A busca aqui é o desenvolvimento e criação de normas comuns que podem ser compartilhadas pelos mais diversos países. Sua utilização é muito comum no âmbito do direito internacional privado.

Esse método, notavelmente desenvolvido na Universidade de Cornell, no âmbito do direito dos contratos, entre os anos cinquenta e sessenta ${ }^{5}$ do século passado, pode ser recentemente observado no processo de harmonização das leis europeias. Esse movimento estimulou o nascimento de grupos, como o Grupo de Trento, liderado por pesquisadores italianos e que tem como objetivo principal "a ambição de identificar um determinado núcleo comum da maior parte do direito privado europeu, dividido em categorias gerais como contratos e propriedades” (BUSSANI; MATTEI, 2000, p. 29) .

O método que busca identificar um núcleo comum é baseado no método funcional, ao mesmo tempo que é combinado com o método de contextualização. O que ele tem de distinto dos outros métodos é sua pretensão de identificar pontos que são compartilhados por diversos sistemas legais para que, a partir disso, possa ser realizado um processo de harmonização de certa parcela da lei.

Assim, esse método procura por similaridades e diferenças, entre sistemas jurídicos, com o intuito de questionar até que ponto a harmonização de certos pontos pode ser possível entre os sistemas comparados, ou até que ponto a lei pode ser interpretada de uma maneira que melhor se enquadre entre diversas tradições legais (VAN HOECKE, 2014, p. 20).

Esses métodos, utilizados de forma conjunta ou separadamente, podem ser considerados atualmente como parte integrante dos principais instrumentos metodológicos utilizados pelos comparatistas em seus trabalhos de pesquisa.

Em que pesem suas diferenças e possíveis conflitos de objetivos, todos eles possuem uma importância inatacável no processo de realizar a comparação. O direito comparado pode e deve utilizar-se de todos eles sempre que for necessário para o processo de aprimoramento da pesquisa que está sendo desenvolvida.

A escolha por um ou alguns deles nesse processo não significa uma preferência absoluta por um em detrimento do outro. Certamente, também não traduz a prevalência de um método melhor ou mais científico. Ao trilhar um caminho metodológico específico, o que o comparatista procura é, fundamentalmente, obter o maior sucesso possível em sua empreitada acadêmica. As escolhas entre os métodos disponíveis significam essencialmente a busca pela potencialização da comparação.

\footnotetext{
${ }^{5}$ A respeito do grupo de Cornell, ver SCHLESINGER, 1961.

${ }^{6}$ Relativamente ao Grupo de Trento, ver FRANKENBERG, 2012, p. 120.
} 
Assim, é preciso que fique claro que não há, em direito comparado, um método melhor ou mais eficaz. Existem métodos que podem variar de acordo com as necessidades de seus operadores ou, nas palavras de Basedow, de seus clientes.

\section{BASEDOW, MÉTODOS E OS CLIENTES DO DIREITO COMPARADO}

A diversidade e importância dos métodos desenvolvidos para a realização da pesquisa comparatista demonstra a proficuidade e o avanço nos esforços no estudo da metodologia do direito comparado. Ao mesmo tempo, o pluralismo dos métodos encontrados hoje entre as pesquisas jurídicas comparadas colabora sobremaneira à potencialização da contribuição do direito comparado em estudos que vão do direito civil ao direito internacional público.

Se num passado recente o direito comparado era quase que exclusivamente objeto de interesse do campo do direito privado, hoje o direito público, especialmente o direito constitucional e o internacional, unem-se a essa disciplina e avançam de maneira notável em diversos pontos de seus conteúdos.

A pluralidade dos métodos de comparação, antes um tema de profundo desacordo entre os estudiosos, hoje parece ter se tornado uma positiva constatação no campo do direito comparado, e vem sendo celebrada por diversos autores.

Nesse mesmo sentido, e preocupado com a valoração da pluralidade de métodos em direito comparado, surge a teoria dos clientes do direito comparado, desenvolvida pelo professor Jürgen Basedow.

Segundo o jurista alemão, a pluralidade do método comparado é fundamental para o desenvolvimento dos estudos que contrapõem sistemas jurídicos. Ao mesmo tempo, a seleção do método que será utilizado pode variar de acordo com as necessidades que pretendem utilizarem-se do conhecimento produzido com o direito comparado (BASEDOW, 2014, p. 821).

Portanto, as mais diversas aspirações que pretendemos alcançar com os estudos comparados não só nos direcionam na escolha do método que será explorado, mas nos vinculam a este caminho.

Como consequência, o que podemos identificar é um grupo de possíveis “clientes” do direito comparado. Eles podem ser, por exemplo, os advogados, as cortes judiciais, o Poder Legislativo do Estado, as agências e organizações internacionais e até mesmo as instituições privadas.

O conhecimento produzido com o direito comparado é, por sua vez, variado, e perpassa a contribuição na descoberta de pontos em comum entre os sistemas jurídicos, a busca por um modelo que irá contribuir para o desenvolvimento de leis nacionais, a preparação para instrumentos 
internacionais uniformizadores, a elucidação de modelos legais de constituição, entre outros (BASEDOW, 2014, p. 822).

Para cada grupo de clientes podemos apurar uma demanda específica no direito comparado. O que devemos levar em consideração é que, assim como as pesquisas em outros campos do direito são conduzidas com uma expectativa vinda de fora do próprio campo do direito, os resultados das pesquisas comparadas também servem a objetivos definidos por esses “clientes”. Há, portanto, um grande e variado conjunto de fins que determinam o estilo e o método das investigações comparativas (BASEDOW, 2014, p. 823).

A importante contribuição que os estudos em direito comparado trazem para o conhecimento jurídico precisa estar alinhada com seus objetivos precípuos. Para isso, a escolha do método propício se faz necessária e tem importância destacada.

A redução dos métodos comparados a apenas um - historicamente, o funcionalista prejudica a pesquisa comparada e sua pretensão de, ao final, resultar em conhecimento a ser compartilhado.

Cada método possui suas potencialidades e fraquezas, e compreendê-las é parte do processo para garantir uma pesquisa comparada mais eficaz, trazendo resultados mais sólidos à questão (ao cliente) que pretendemos responder.

Paralelamente, hoje fica claro que a utilização dos métodos comparados pode e deve ser feita de maneira conjunta, permitindo uma análise mais ampla, sem perder o rigor, e mais profunda, sem perder seu objetivo inicial.

O grande desafio, hoje, para o comparatista, é realizar um trabalho metodológico que seja, ao mesmo tempo, rigoroso e capaz de transitar entre os diversos métodos existentes. Paralelamente, essa dificuldade é acentuada pela característica natural de interdisciplinaridade que todo estudo comparado contém.

Assim, fica evidenciado que todas as formas de investigação comparativa são apropriadas. O que as diferencia é o cabimento ou não de sua aplicação em relação a cada pesquisa específica.

Assim, completa bem Basedow (2014, p. 836),

[...] uma aprovação ou uma rejeição irrestrita de um simples método no direito comparado deve falhar cedo ou tarde. O mais importante para cada investigação comparada é encontrar a perspectiva ou as perspectivas que melhor casem com o sujeito ou a investigação e que permitam a otimização do entendimento da lei estrangeira sob escrutínio.

O direito comparado, portanto, não pode ser entendido de maneira dogmática. Ele deve ser respeitado como a ciência empírica que ele é, não sendo capaz de ser entendido como um sistema intelectual fechado. Os vários métodos existentes não são excludentes e, ao contrário, podem e devem 
ser utilizados em conjunto, permitindo um maior rigor e profundidade da pesquisa.

A pesquisa comparativa, por sua vez, possui interesses e desafios definidos, e seu objeto é resultado direto de uma demanda do mundo real. Sendo assim, a pesquisa comparativa pode e deve responder a essas demandas de diversas maneiras, sempre com o intuito de satisfazer as pretensões que moveram a pesquisa. Os métodos do direito comparado são os parceiros ideais e essenciais na busca pela solução desses desafios.

\section{CONCLUSÃO}

O estudo do direito comparado é marcado pela sua preocupação com temas que transitam pela metodologia do direito. Em que pese a enorme produção acadêmica a respeito, somente recentemente o método em direito comparado deixou de ser entendido fora de proposições conflitivas e, portanto, desagregadoras.

Hoje podemos identificar uma construção que vai se tornando pacífica entre os estudiosos da metodologia do direito comparado. Há, cada vez mais, o entendimento de que é fundamental compreender a importância da existência de uma pluralidade de métodos na pesquisa comparativa.

Essa pluralidade, por sua vez, não é só uma importante característica do direito comparado, mas parte essencial do processo de pesquisa em torno da disciplina, podendo não só ser aplicada de maneira individual ou conjunta, mas de acordo com os interesses do objeto pesquisado.

Em suma, o direito comparado hoje é entendido como uma disciplina que possui um rol de métodos. Esses métodos não são considerados excludentes. Ao contrário - quando bem aplicados de forma conjunta, contribuem de maneira fundamental para sofisticar a pesquisa científica.

Ao mesmo tempo, a escolha do método a ser utilizado não é impositiva, podendo variar de acordo com os interesses do pesquisador. Esses interesses, por sua vez, são resultado de fatores que são tanto internos quanto externos à pesquisa, e que veem na pluralidade dos métodos um importante aliado para a construção de uma produção acadêmica com resultados que são não só mais produtivos e confiáveis, mas também mais eficazes em seu aproveitamento no campo da prática jurídica.

Assim, essa nova perspectiva relacionada aos métodos do direito comparado contribui para que essa disciplina continue a ser, cada dia mais, um significativo campo do direito num mundo cada vez mais internacionalizado.

\section{REFERÊNCIAS}

ADAMS, Maurice. Doing What Doesn't Come Naturally. On the Distinctiveness of Comparative 
Law. In: VAN HOECKE, Mark (Ed). Methodologies of Legal Research: Which Kind of Method for What Kind of Discipline? Oxford: Hart Publishing, 2011.

AGAMBEN, Giorgio. The Signature of All Things: On Method. Translated by Luca D'Isanto and Kevin Attell. New York: Zone, 2009.

BASEDOW, Jürgen. Comparative Law and its Clients. The American Journal of Comparative Law, v. 62, 2014, p. 821-857.

BELL, John. La comparaison en droit public. Melanges em l'honneur de Denis Tallon. Paris: Société de législation comparée, 1999.

BERCEA, Raluca. Tout comparaison des droits est une fiction. In: LEGRAND, Pierre. Comparer les droits résolument. Paris: PUF, 2009. p. 41-68.

BERGEL, J. L. Méthodologie Juridique. Paris: Presses Universitaires de France, 2001.

BOBBIO, Norberto. Metodo. In: Contributi ad um dizionario giuridico. Torino: Giappichelli Editore, 1994.

BONILLA MALDONADO, Daniel (Org.). Teoría del derecho y transplantes jurídicos. Bogotá: Siglo del Hombre Editores, Universidad de los Andes, Pontificia Universidad Javeriana, 2009.

BRAND, Oliver. Conceptual Comparisons: Towards a Coherent Methodology of Comparative Legal Studies. In: Brooklyn Journal of International Law, v. 32, Issue 2, 2007, p. 405-466.

BUSSANI, Mauro; MATTEI, Ugo. Making European Law. Essays on the «common» core project. Quaderni del Dipartimento di Scienze Giuridiche, Trento, 2000.

CHAMPEIL-DESPLATS, Véronique. Méthodologies du Droit et des Sciences du Droit. Paris: Dalloz, 2014.

CHEVALLIER, J. Science administrative. Paris: LGDJ, 1978.

CONSTANTINESCO, L. J. Traité de droit comparé: La méthode comparative. Paris: LGDJ, 1974.

CORTEN, O. Méthodologie du droit international public. Bruxelles: Éditions de L’Université de Bruxelles, 2009.

DAVID, René. Os grandes sistemas do direito contemporâneo. São Paulo: Martins Fontes, 2002.

DELMAS-MARTY, Mireille. The Contribution of Comparative Law to a Pluralist conception of International Criminal Law. In: Journal of International Criminal Justice, vol. 1, 2003, p. 13.

DRAGO, R. Droit Comparé. In: ALLAND, D.; RIALS, S. (Org.). Dictionnaire de la culture juridique. Paris: PUF, 2003.

EBERLE, Edward J. The Method and Role of Comparative Law. In: Washington University Global Studies Law Review, v. 8, n. 3, 2009. 
FAUVARQUE-COSSON, Bénédicte. Deux Siècles d'évolution du droit compare. Revue Internationale de Droit Compare, v. 63, n. 3, 2011, p. 527.

. La réponse. In: Revue Internationale de Droit Compare, v. 55, 2003, p. 530-537.

. Vers un Universalisme Renouvelé: Quelles em sont les Manifestations em Droit? In: Diogène, v. 219, 2007, p. 68-81.

FLETCHER, George P. Comparative Law as a Subversive Discipline. The American Journal of Comparative Law, v. 46, n. 4 (Autumn, 1998), p. 683-700.

FRÄNDBERG, Åke. Systematics of Legal Concepts. Scandinavian Studies in Law, 1987-31, p. 83115.

FRANKENBERG, Günther. Comparing constitutions: Ideas, ideals and ideology - toward a layered narrative. In: International Journal of Constitutional Law, v. 4, n. 3, 2006.

Critical Comparisons: Re-thinking Comparative Law. In: Harvard International Law Journal, v. 26, n. 2, 1985, p. 411-456.

. How to do Projects with Comparative Law: Notes of an Expedition to the Common Core. In: MONATERI, Pier Giuseppe (Ed.). Methods of Comparative Law. UK: Edward Elgar Publishing, 2012.

. Stranger than Paradise: Identity \& Politics in Comparative Law. In: Utah Law Review, v. 259, 1997, p. 259-263.

GILROY, John Martin. A proposal for "Philosophical Method" in Comparative and International Law. In: Pace International Law Review, v. 1, 2009, p. 1-14.

GINSBURG, Tom; DIXON, Rosalind (Org.). Comparative Constitutional Law. Northampton: Edward Elgar, 2011.

GLANERT, Simone. Method? In: MONATERI, Pier Giuseppe (Ed.). Methods of Comparative Law. UK: Edward Elgar Publishing, 2012, p. 61-81.

GLENN, H. Patrick. Legal Traditions of the World. Oxford: Oxford University Press, 2014.

GORDLEY, James. Comparative Law and Legal History. In: REIMANN, Mathias; ZIMMERMANN, Reinhard. The Oxford Handbook of Comparative Law. Oxford: Oxford University Press, 2012.

GRAWITZ, Madelaine. Méthodes des Sciences Sociales. Paris: Dalloz, 2001.

HAGE, Jaap. Comparative Law as Method and the Method of Comparative Law. In: ADAMS, Maurice; HEIRBAUT, Dick (Ed.). The Method and Culture of Comparative Law. Essays in Honour of Mark Van Hoecke. Oxford: Hart Publishing, 2014. 
HIRSCHL, Ran. The Question of Case Selection in Comparative Constitutional Law. American Journal of Comparative Law, n. 53, v. 123, 2005, p. 125-155.

HUG, Walther. The History of Comparative Law. In: Harvard Law Review, v. 45, n. 6, 1932, p. 1.027-1.070.

HUSA, Jaakko. Research Designs of Comparative Law - Methodology or Heuristics? The Journal of Comparative Law, v. 9, 2015.

JALUZOT. Béatrice. Méthodologie du droit comparé: bilan et prospective. In: Revue internationale de droit comparé, 2005, p. 29-48.

KISS, Alexandre Charles. Droit Comparé et Droit International Public. In: Revue internationale de droit comparé, v. 24, 1972, p. 5-12.

LARENZ, Karl. Metodologia da Ciência do Direito. Lisboa: Fundação Calouste Gulbenkian, 2014.

LEGRAND, Pierre. Comparer les droits, résolument. Paris: PUF, 2009.

. Le Droit Comparé. Paris: PUF, 1999.

; MUNDAY, Roderick. Comparative Legal Studies: Traditions and Transitions. Cambridge: Cambridge University Press, 2011.

LOSANO, Mario G. Os grandes sistemas jurídicos. São Paulo: Martins Fontes, 2007.

MATTEI, Ugo. Comparative Law and Economics. Michigan: University of Michigan Press, 1999.

; MAMLYUK, Boris. Comparative International Law. In: Brooklyn International Journal, v. 36, 2011, p. 385-452.

MICHAELS, Ralf. The Functional Method of Comparative Law. In: REIMANN, Mathias; ZIMMERMANN, Reinhard. The Oxford Handbook of Comparative Law. Oxford: Oxford University Press, 2008, p. 339-382.

MIRKINE-GUETZÉVITCH, Boris. Les méthodes d'étude du droit constitutionnel compare. In: Revue Internationale de Droit Compare, v. 1, n. 4, 1949, p. 397-417.

MONATERI, Pier Giuseppe (Ed.). Methods of Comparative Law. UK: Edward Elgar Publishing, 2012.

MUIR-WATT, Horatia. La function subversive du droit compare. Revue International de Droit Comparé, v. 52, n. 3, 2000, p. 503-527.

MÜLLER, Friedrich. Metodologia do Direito Constitucional. 4. ed. São Paulo: Editora dos Tribunais, 2010.

OBIORA, L. Amede. Toward an Auspicious Reconciliation of International and Comparative Analyses. The American Journal of Comparative Law, v. 43, 1998, p. 699-682. 
OGUS, Anthony. Competition Between National Legal Systems: A Contribution of Economic Analysis to Comparative Law. In: International and Comparative Law Quarterly, v. 48, n. 2, 1999, p. 405-418.

ÖRÜCÜ, Esin. Developing Comparative Law. In: ÖRÜCÜ, E.; NELKEN, D. (Ed). Comparative Law: A Handbook. Oxford: Hart Publishing, 2007.

PLATSAS, Antonios Emmanuel. The Functional and the Dysfunctional in the Comparative Method of Law: Some Critical Remarks. In: Electronic Journal of Comparative Law, v. 12.3, 2008. Disponível em: <https://goo.gl/bULfsW>. Acesso em: 30 abr. 2016.

PONTHOREAU. Marie-Claire. Droit(s) constitutionnel(s) Comparé(s). Paris: Economica, 2010.

REIMANN, Mathias. Beyond National Systems: A comparative Law for the International Age. Tulane Law Rewiew, v. 75, 2001, p. 1.103-1.119.

; ZIMMERMANN, Reinhard. The Oxford Handbook of Comparative Law. Oxford: Oxford University Press, 2008.

ROBERTS, Anthea. Comparative International Law? The Role of National Courts in Creating and Enforcing International Law. International and Comparative Law Quarterly, v. 60, 2011, p. 57-92.

ROSENFELD, Michel; SAJÓ, András (Org.). The Oxford Handbook of Comparative Constitutional Law. Oxford: Oxford University Press, 2012.

SACCO, Rodolfo. La comparasion juridique au servisse de la connaissance du droit. Paris: Economica, 1991.

Legal Formants: A Dynamic Approach to Comparative Law. The American Journal of Comparative Law, v. 39, n. 1, 1991, p. 1-34.

SAMUEL, Geoffrey. An Introduction to Comparative Law Theory and Method. Oxford: Hart Publishing, 2014.

. Taking Methods Seriously (Part Two). In: Journal of Comparative Law, 2007.

SCHLESINGER, Rudolf. The Common Core of Legal Systems: An Emerging Subject of Comparative Study. Leyden: A.W. Sijthoff, 1961.

TUSHNET, Mark. Advanced Introduction to Comparative Constitutional Law. Northampton: Edward Elgar Publishing, 2014.

VALCKE, Catherine; GRELLETTE, Mathew. Three Functions of Function in Comparative Legal Studies. In: ADAMS, Maurice; HEIRBAUT, Dirk (Ed.). The Method and Culture of Comparative Law: Essays in Honour of Mark Van Hoecke. Oxford: Hart Publishing, 2014.

VAN HOECKE, Mark (Org.). Epistemology and Methodology of Comparative Law. Oxford: Hart Publishing, 2004. 
(Org.). Methodologies of Legal Research: What Kind of Method for What Kind of Discipline? Oxford: Hart Publishing, 2013.

Methodology of Comparative Legal Research. 2014. Disponível em: <https://goo.gl/dA2YSp>. Acesso em: 30 abr. 2016.

VILLA, Vittorio. La science du droit. Paris: LGDJ, 1990.

ZWEIGERT, K.; KÖTZ, H. An Introduction to Comparative Law. New York: Oxford University Press, 1998.

\title{
METHOD(S) IN COMPARATIVE LAW
}

\begin{abstract}
This paper aims to develop an analysis of the method used within comparative law. To achieve this objective, the research goes over some steps. The first one is to recover the debate about the meaning and importance of methodology and method under the law. The second moment is dedicated to analyze the concept of method within the comparative law framework and on giving the reader a nonexhaustive list of methods used in the subject. Finally, and in order to present a new perspective, the paper aligns with the position that considers that, in a comparative basis, comparative law does not have a single most appropriate and effective method. Instead, the paper argues that there is a plurality of methods in comparative law. They are complementary and can be used concurrently making comparative studies possible to reach more accurate results. The choice of the method(s) is, therefore, a free and legitimate choice of the researcher and will vary according to his/her scientific interests.
\end{abstract}

\section{KEYWORDS}

Method. Methodology. Comparative law. 